\title{
Instrumented treadmills: establishing measurement properties is necessary for evaluating clinical interventions
}

\author{
Lloyd Reed ${ }^{1 *}$, Stephen Urry', Scott Wearing ${ }^{2,3}$ \\ From Australasian Podiatry Council Conference 2013 \\ Sydney, Australia. 2-5 June 2013
}

\section{Background}

Instrumented treadmills that provide basic gait parameters in near real-time are emerging as valuable outcome tools in both clinical and research settings. Significant changes in step length and peak vertical force in the order of $2 \mathrm{~cm}$ and $20-70 \mathrm{~N}$ have been reported with footwear interventions and neurological disorders using these systems. However, published data about the systems' measurement properties is lacking. This study evaluated the within- and between day repeatability of spatiotemporal parameters and vertical ground reaction forces (vGRF) measured by a new instrumented treadmill system.

\section{Methods}

Thirty three healthy adults (mean age, $21.5 \pm 2.8$ years) walked on an instrumented treadmill system (FDMTHM-S, Zebris Medical GmbH) at preferred speeds, on three separate occasions. Spatial, temporal and vGRF were collected over a 30-second capture period. Repeated measures ANOVAs were used to assess between-session differences in gait parameters, while agreement within- and between days were evaluated using $95 \%$ limits of agreement.

\section{Results}

Statistically significant differences were found for the majority $(14 / 16)$ of temporospatial and kinetic gait parameters over the three sessions $(P<.01)$. The minimum change that could be detected with $95 \%$ confidence ranged from $3-16 \%$ for temporal parameters, $12-32 \%$ for spatial parameters, and $5-18 \%$ for kinetic parameters.

\footnotetext{
* Correspondence: I.reed@qut.edu.au

${ }^{1}$ School of Clinical Sciences, Queensland University of Technology, Kelvin Grove, Qld, 4059, Australia

Full list of author information is available at the end of the article
}

\section{Conclusion}

Changes in gait parameters measured by the same treadmill and previously attributed to clinical interventions and neuromuscular pathology, fall within the measurement error of the treadmill determined in this study. The findings highlight the importance of determining the measurement properties of outcome tools in evaluating clinical interventions.

\section{Author details}

${ }^{1}$ School of Clinical Sciences, Queensland University of Technology, Kelvin Grove, Qld, 4059, Australia. 'Faculty of Health Sciences and Medicine, Bond University, Gold Coast, Qld, 4229, Australia. ${ }^{3}$ Centre of Excellence for Applied Sports Science Research, Queensland Academy of Sport, Qld, 4109, Australia.

Published: 31 May 2013

doi:10.1186/1757-1146-6-S1-P12

Cite this article as: Reed et al:: Instrumented treadmills: establishing measurement properties is necessary for evaluating clinical interventions. Journal of Foot and Ankle Research 2013 6(Suppl 1):P12.

Submit your next manuscript to BioMed Central and take full advantage of:

- Convenient online submission

- Thorough peer review

- No space constraints or color figure charges

- Immediate publication on acceptance

- Inclusion in PubMed, CAS, Scopus and Google Scholar

- Research which is freely available for redistribution 